\title{
Influence of $\mathrm{TiO}_{2}$ particle size and conductivity of the $\mathrm{CuCrO}_{2}$ nanoparticles on the performance of solid-state dye-sensitized solar cells
}

\author{
M ASEMI ${ }^{1,2}$ and M GHANAATSHOAR ${ }^{1,2, *}$ \\ ${ }^{1}$ Laser and Plasma Research Institute, Shahid Beheshti University, G.C., Evin, 1983969411 Tehran, Iran \\ ${ }^{2}$ Solar Cells Research Group, Shahid Beheshti University, G.C., Evin, Tehran 1983969411, Iran \\ *Author for correspondence (m-ghanaat@sbu.ac.ir)
}

MS received 15 May 2016; accepted 8 May 2017; published online 28 November 2017

\begin{abstract}
Solid-state dye-sensitized solar cells have been fabricated with mesoporous $\mathrm{TiO}_{2}$ photoanode and N719 dye as photosensitizer. First, $\mathrm{TiO}_{2}$ and non-doped, $\mathrm{Zn}$ - and $\mathrm{Mg}$-doped $\mathrm{CuCrO}_{2}$ nanoparticles have been synthesized by sol-gel method. In addition, the $\mathrm{TiO}_{2}$ pastes have been prepared through Pechini-type sol-gel method. The effect of $\mathrm{TiO}_{2}$ particle size, mesoporous $\mathrm{TiO}_{2}$ photoanode thickness and solid-state electrolyte thickness on the efficiency of the fabricated devices has been investigated. Our results show that in spite of the low amount of dye loading for photoanode with large $\mathrm{TiO}_{2}$ nanoparticles $(80-180 \mathrm{~nm})$, the dye-sensitized solar cell made from it has higher efficiency than that constructed from the photoanode comprising of small particles about $10-15 \mathrm{~nm}$ in size. The higher efficiency is attributed to the longer diffusion length of electrons because of a better electron transport and penetration of a large amount of $\mathrm{CuCrO}_{2}$ nanoparticles in the porous structure of $\mathrm{TiO}_{2}$ photoanode. By using the doped $\mathrm{CuCrO}_{2}$ nanoparticles, the efficiency has been increased from $0.027 \%$ for $\mathrm{TiO}_{2} / \mathrm{N} 719$ dye/CuCrO 2 to $0.033 \%$ for $\mathrm{TiO}_{2} / \mathrm{N} 719$ dye/CuCrO $2: \mathrm{Zn}$ and further increased to $0.042 \%$ for $\mathrm{TiO}_{2} / \mathrm{N} 719$ dye/CuCrO $2: \mathrm{Mg}$. The efficiency enhancement by doping is ascribed to the conductivity improvement due to the presence of impurity atoms.
\end{abstract}

Keywords. Solid-state dye-sensitized solar cells; sol-gel method; $\mathrm{TiO}_{2}$ nanoparticle; $\mathrm{CuCrO}_{2}$ nanoparticles; electrical transport.

\section{Introduction}

Dye-sensitized solar cells (DSSCs) have attracted great attention over the past decade due to high-energy conversion efficiency, simple manufacturing process and low production cost [1-4]. Transparent conductive oxides as substrate, mesoporous metal oxide semiconductor thick films, dye sensitizers, electrolytes and counter electrodes are the main components of a typical DSSC [5-8]. Recently, the highest conversion efficiency of a $\mathrm{TiO}_{2}$-based DSSC has been reported by using molecularly engineered porphyrin dye, coded SM315 and an organic liquid-based electrolyte containing cobalt (II/III) redox couple [9]. However, the leakage and evaporation of the organic solvent in the liquid electrolyte has been a serious challenge for long-term practical applications, especially under elevated temperature condition $[10,11]$. The leakage of toxic organic solvents and evaporation of volatile iodine ions in liquid electrolyte reduces the charge carrier concentration. The reduction in charge carrier concentration increases the overall internal resistance and finally the efficiency of the device is decreased. Many efforts have been made to overcome this problem and it has been found that instead of liquid electrolyte the use of solid-state electrolytes, such as polymer electrolytes, which are defined as polymer materials complexed with salts, plastic crystal electrolytes, inorganic p-type semiconductors, organic hole conductors and room temperature molten salts can be effective [12-14]. Nevertheless, energy conversion efficiency of the fabricated devices with these solid-state electrolytes is not usually satisfactory. The low conversion efficiency is mainly attributed to the low ionic conductivity of the electrolyte and/or poor electrode/electrolyte interfacial contact [15].

To date, several inorganic copper-based compounds such as $\mathrm{CuI}, \mathrm{CuBr}$ and $\mathrm{CuSCN}$ have been used as inorganic hole transfer materials (HTMs) because of their good conductivity and appropriate band positions but they are unstable and tend to degrade quickly [16-19]. Hence, finding a suitable inorganic p-type semiconductor with desired properties such as appropriate band gap, band positions and a method for its deposition is a great challenge. Wide band-gap p-type oxide semiconductors can be regarded as suitable candidates for inorganic HTMs because of their good conductivity, stability and appropriate band positions [15]. Previously, Bandara and Weerasinghe [20] have reported the use of $\mathrm{NiO}$ nanoparticles as an inorganic $\mathrm{HTM}$ in $\mathrm{TiO}_{2}$-based DSSCs. In 2007, the photovoltaic parameters of the solid-state DSSCs utilizing $\mathrm{CuAlO}_{2}$ nanoparticles in $\mathrm{TiO}_{2} / \mathrm{N} 719$ dye/CuAlO structure have been reported by Bandara and Yasomanee [21] 
Then, Lee et al $[22,23]$ prepared $\mathrm{n}-\mathrm{TiO}_{2} / \mathrm{p}-\mathrm{NiO}$ heterojunction electrodes for all-solid-state DSSCs. Numerous delafossite oxides $\left(\mathrm{CuAlO}_{2}, \mathrm{CuGaO}_{2}\right.$ and $\left.\mathrm{CuCrO}_{2}\right)$ have also been utilized to serve as photocathode materials in p-type DSSCs in replacement of conventional $\mathrm{NiO}$; but their reported efficiencies are much lower than those of n-type DSSCs. The energy conversion efficiency of p-type DSSCs with small size $\mathrm{CuAlO}_{2}$ particles $(35 \mathrm{~nm})$, was reported to be around $0.037 \%$ [24]. Xiong et al [6] have reported an overall power conversion efficiency of $0.132 \%$ with $\mathrm{CuCr}_{0.9} \mathrm{Mg}_{0.1} \mathrm{O}_{2}$ dyesensitized photocathode under optimized conditions, but with P1 dye. On the other hand, Renaud et al [25] have investigated the effect of $\mathrm{Mg}$ doping on the photovoltaic performance of $\mathrm{CuGaO}_{2}$-based p-type DSSCs and achieved a maximum efficiency of $0.045 \%$.

The purpose of this work is construction and optimization of $\mathrm{TiO}_{2} / \mathrm{N} 719$ dye $/ \mathrm{CuCrO}_{2}$ solid-state DSSCs. We study the effect of $\mathrm{TiO}_{2}$ particle size on the efficiency of the fabricated devices. The thickness of the $\mathrm{TiO}_{2}$ photoanode and the solidstate electrolyte is also important to enhance its efficiency. For further improvement, we use doped $\mathrm{CuCrO}_{2}$ nanoparticles. Addition of divalent cations in the $\mathrm{CuCrO}_{2}$ lattice can increase the p-type conductivity and thus can influence the efficiency of the solid-state DSSCs.

\section{Experimental}

The $\mathrm{TiO}_{2}$ nanoparticles with two distinct diameters of about $10-15$ and $80-180 \mathrm{~nm}$ in the anatase phase were synthesized from titanium tetraisopropoxide (TTIP, Samchun Chemical Co., Korea), hydrochloric acid ( $\mathrm{HCl}$, Ameretat Co., Iran), anhydrous alcohol (Merck Co., Germany) and distilled water by sol-gel method. Initially, $10 \mathrm{ml}$ of TTIP was dissolved in $10 \mathrm{ml}$ anhydrous alcohol (ethanol) and stirred to obtain a clear solution. Then, $5 \mathrm{ml}$ of distilled water was slowly added into the solution, which was stirred for $2 \mathrm{~h}$ at room temperature. The $\mathrm{pH}$ value of the solution was adjusted at 2.0 by dropwise addition of $0.1 \mathrm{M}$ hydrochloric acid with vigorous stirring. The resultant solution was aged for $24 \mathrm{~h}$ at room temperature. After that the obtained precursor was washed several times with distilled water and anhydrous alcohol and dried at $100^{\circ} \mathrm{C}$ for $12 \mathrm{~h}$. Finally, the dried powders were annealed at 400 and $600^{\circ} \mathrm{C}$ for $3 \mathrm{~h}$ in a laboratory electric furnace (Azar Furnace Co., Model F35L-1200, Iran). Heat treatment at different temperatures will lead to different particle sizes.

The sol-gel method was similarly employed for synthesis of $\mathrm{CuCrO}_{2}$ nanoparticles. We used copper acetate monohydrate $\left(\mathrm{Cu}\left(\mathrm{CH}_{3} \mathrm{COO}\right)_{2} \cdot \mathrm{H}_{2} \mathrm{O}\right.$, Merck Co., Germany) and chromium nitrate nonahydrate $\left(\mathrm{Cr}\left(\mathrm{NO}_{3}\right)_{3} \cdot 9 \mathrm{H}_{2} \mathrm{O}\right.$, Merck Co., Germany) as starting materials and 2-methoxyethanol $\left(\mathrm{CH}_{3}\left(\mathrm{CH}_{2}\right)_{2} \mathrm{OOH}\right.$, Merck Co., Germany) as a solvent. Furthermore, zinc acetate dihydrate $\left(\mathrm{Zn}\left(\mathrm{CH}_{3} \mathrm{COO}\right)_{2} \cdot \mathrm{H}_{2} \mathrm{O}\right.$, Merck Co., Germany) and magnesium nitrate hexahydrate $\left(\mathrm{Mg}\left(\mathrm{NO}_{3}\right)_{2} \cdot 6 \mathrm{H}_{2} \mathrm{O}\right.$, Merck Co. Germany) were used as dopant sources. The precursor solutions were prepared by dissolving copper acetate monohydrate and chromium nitrate nonahydrate in 2-methoxyethanol at $60^{\circ} \mathrm{C}$. In order to fabricate the metal-doped $\mathrm{CuCrO}_{2}$ nanoparticles, zinc acetate dihydrate and magnesium nitrate hexahydrate were added to the precursor solution. The copper acetate/chromium nitrate molar ratio was fixed at 1:1. The concentration of copper acetate in the initial solutions was kept to be $0.7 \mathrm{M}$ and the concentration of $\mathrm{Zn}$ and $\mathrm{Mg}$ as dopants was $5 \%$ with respect to $\mathrm{Cr}$ in the solutions. The prepared precursor solutions were stirred at $60^{\circ} \mathrm{C}$ for $3 \mathrm{~h}$ to yield clear, homogenous and deep green solutions. The obtained solutions were dried at $110^{\circ} \mathrm{C}$ for $3 \mathrm{~h}$. Finally, the dried powders were annealed in air at $900^{\circ} \mathrm{C}$ for $1 \mathrm{~h}$ in the furnace.

The $\mathrm{TiO}_{2}$ pastes were prepared by Pechini-type sol-gel method $[26,27]$. To fabricate DSSCs, F-doped $\mathrm{SnO}_{2}$ (FTO) conducting glass substrates were first cleaned in ethanol and acetone solution using an ultrasonic bath for $10 \mathrm{~min}$ and then rinsed with ethanol. The $\mathrm{TiO}_{2}$ pastes were coated on cleaned FTO conducting glasses by spin coating method (using aBacker Viera Trading SC-410 spin-coater, Iran). The $\mathrm{TiO}_{2}$ mesoporous films were aged at room temperature for $15 \mathrm{~min}$ and then sintered at $450^{\circ} \mathrm{C}$ for $1 \mathrm{~h}$ in a laboratory electric furnace (Azar Furnace Co., Model F35L-1200, Iran). Subsequently, the sintered $\mathrm{TiO}_{2}$ mesoporous films were immersed into $0.4 \mathrm{mM}$ ethanol solution of N719 dye for 24 $\mathrm{h}$ to allow for sufficient dye adsorption. Then, the films were rinsed with anhydrous ethanol and finally dried at the ambient condition. In this way, the dye-sensitized $\mathrm{TiO}_{2}$ electrodes were obtained. In order to deposit the $\mathrm{CuCrO}_{2}$ nanoparticles on the dye-sensitized $\mathrm{TiO}_{2}$ electrode, the p-type nanoparticles were dispersed in ethanol solution. The solution of $\mathrm{CuCrO}_{2}$ nanoparticles was carefully deposited on the mesoporous $\mathrm{TiO}_{2}$ electrode by the spin coating technique. The $\mathrm{CuCrO}_{2}$ solid-state electrolyte thickness was controlled by the speed of rotation. The platinized conducting glass electrode was prepared by $\mathrm{H}_{2} \mathrm{PtCl}_{6}$ solution ( $5 \mathrm{mM}$ in 2-propanol) on a clean FTO substrate by sol-gel spin coating technique (500 rpm for $10 \mathrm{~s})$. The precursor film was first dried at $150^{\circ} \mathrm{C}$ and then the obtained film was annealed at $450^{\circ} \mathrm{C}$ for $30 \mathrm{~min}$. Then, the $\mathrm{Pt}$ electrode was placed over the dye-adsorbed $\mathrm{TiO}_{2}$ electrode and the two electrodes were held with a binder clip.

The phase and crystal structure of the synthesized nanoparticles were identified by X-ray diffraction (XRD) with a PANalytical X'Pert Pro powder diffractometer with $\mathrm{Cu} \mathrm{K} \alpha=$ $1.5406 \AA$ radiation. The particle size and the thickness of the $\mathrm{TiO}_{2}$ and $\mathrm{CuCrO}_{2}$ layers were analysed using field emission scanning electron microscopy (FESEM) (TESCAN mira $3 \mathrm{xmu}$ ) and cross-sectional scanning electron microscopy (HITACHI S-4160 SEM), respectively. The amount of the N719 dye adsorbed on the $\mathrm{TiO}_{2}$ mesoporous photoanode, which is related to the active surface area of the $\mathrm{TiO}_{2}$ layer, was determined with $3648 \mathrm{UV}-\mathrm{Vis}$ Avantes spectrophotometer. We inspected the performance of the fabricated DSSCs by recording the current-voltage curve with computer-controlled digital source metre (Sharif Solar, IV-25) and a solar simulator 
(AM 1.5G, Sharif Solar, SIM-1000) as a light source calibrated to $100 \mathrm{~mW} \mathrm{~cm}^{-2}$ with a standard Si solar cell. Hall effect and resistivity measurements were carried out by employing the van der Pauw configuration. The magnetic field in Hall effect measurements was fixed at $400 \mathrm{mT}$.

\section{Results and discussion}

Figure 1a shows the XRD patterns of the synthesized $\mathrm{TiO}_{2}$ nanoparticles heat-treated at different temperatures for $3 \mathrm{~h}$. XRD studies show that the synthesized $\mathrm{TiO}_{2}$ nanoparticles are in pure anatase phase, and the crystal structures agree with the corresponding JCPDS data (JCPDS Card No. 211272). High purity and crystallinity of the synthesized $\mathrm{TiO}_{2}$ particles are revealed by the appearance of clear and sharp peaks. The results show that the intensity of the peaks moderately increases with annealing temperature. The crystallite size of the prepared $\mathrm{TiO}_{2}$ nanoparticles at 400 and $600^{\circ} \mathrm{C}$ were estimated by Debye-Scherrer equation to be about 9.3 and $14.6 \mathrm{~nm}$, respectively [28]. The results are in agreement with other literature [29]. Similarly, XRD patterns of synthesized $\mathrm{CuCrO}_{2}$ nanoparticles are shown in figure $1 \mathrm{~b}$. The diffraction peaks in the figure are indexed to the delafossite-type phase of $\mathrm{CuCrO}_{2}$ nanoparticles (JCPDS Card No. 89-6744) with a rhombohedral unit cell. These results indicate that highly crystalline and single phase $\mathrm{CuCrO}_{2}$ nanoparticles have been synthesized with 5\% Mg and $\mathrm{Zn}$ dopants. The estimated crystallite size in the preferential direction is about 32.3, 29.8 and 28.7 for undoped, $\mathrm{Zn}$ - and $\mathrm{Mg}$-doped $\mathrm{CuCrO}_{2}$ nanoparticles, respectively.

In conjunction with the crystallite size growth, the size of the nanoparticles can also be increased with annealing temperature. In figure 2, FESEM images of $\mathrm{TiO}_{2}$ nanoparticles show that the size of the fabricated $\mathrm{TiO}_{2}$ nanoparticles is in the range of $10-15 \mathrm{~nm}$ (sample A) and $80-180 \mathrm{~nm}$ (sample B), respectively. Figure 3 a shows the J-V characteristics of both the solar cells consisting of $\mathrm{TiO}_{2}$ photoanodes with different particle sizes (with the same thickness of about $10 \mu \mathrm{m}$ ) and undoped $\mathrm{CuCrO}_{2}$ nanoparticles as solid-state electrolyte (with thickness of about $3.5 \mu \mathrm{m}$ ). The short-circuit current density $\left(J_{\mathrm{SC}}\right)$ and open-circuit voltage $\left(V_{\mathrm{OC}}\right)$ of sample $\mathrm{B}$ are $0.127 \mathrm{~mA} \mathrm{~cm}^{-2}$ and $215 \mathrm{mV}$, respectively, which are higher than those of sample $\mathrm{A}\left(0.058 \mathrm{~mA} \mathrm{~cm}^{-2}\right.$ and $\left.170 \mathrm{mV}\right)$, leading to a significant enhancement of efficiency $(0.010 \%$ compared to $0.0037 \%$ for sample A). It is well known that the $\mathrm{TiO}_{2}$ photoanode constructed from the smaller particles has greater surface area than that having larger particles [30] and therefore, the amount of the adsorbed dye by the $\mathrm{TiO}_{2}$ photoanode fabricated with small particles is more [31]. UV-Vis absorption spectra of desorbed $\mathrm{N} 719$ dye from the $\mathrm{TiO}_{2}$ photoanode confirms our statement about the amount of adsorbed dye on the surface of nanoparticles (figure $3 \mathrm{~b}$ ). To perform this analysis, we collected the desorbed $\mathrm{N} 719$ dye from $\mathrm{TiO}_{2}$ photoanode by immersing the $\mathrm{TiO}_{2}$ photoanode in $0.05 \mathrm{M} \mathrm{NaOH}$ in an ethanol and water aqueous solution with 1:1 volume
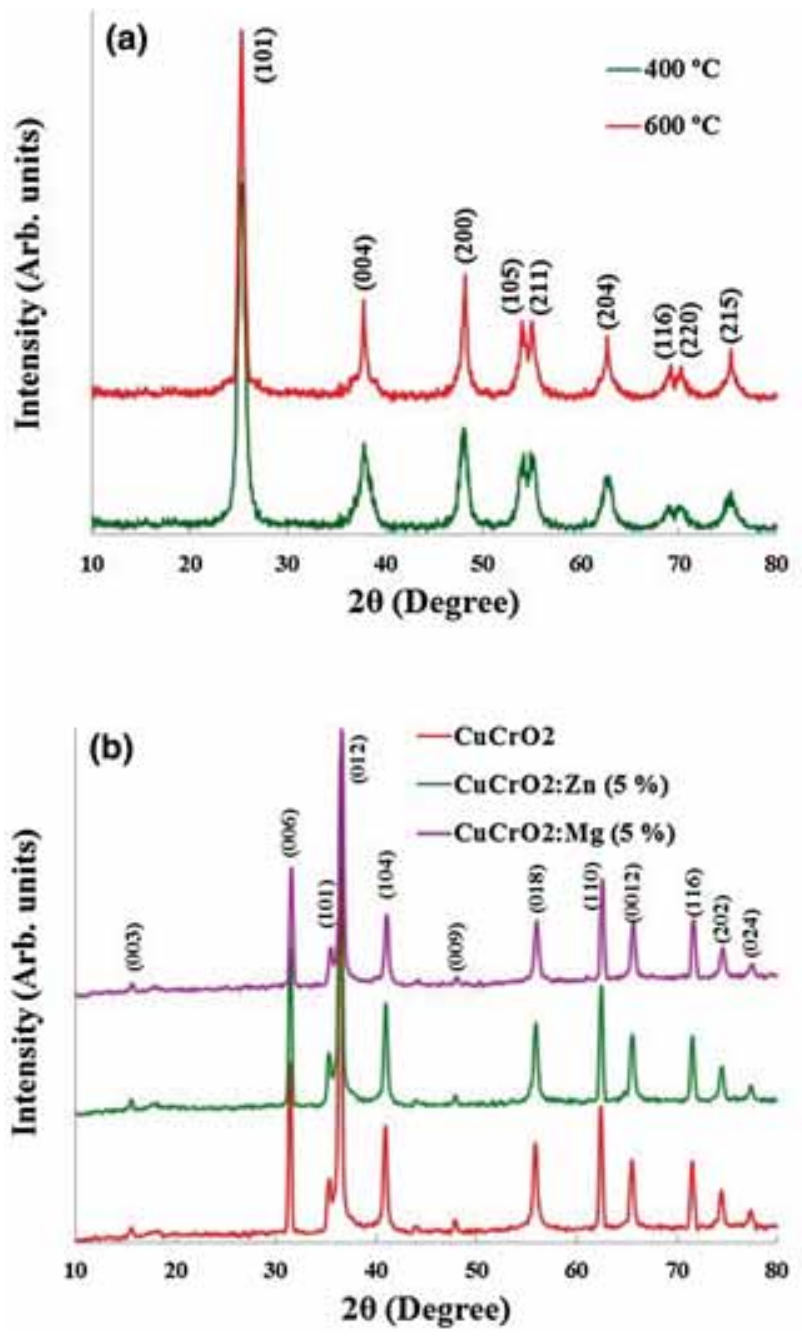

Figure 1. XRD patterns of synthesized (a) $\mathrm{TiO}_{2}$ nanoparticles and (b) undoped, $\mathrm{Zn}$ - and $\mathrm{Mg}$-doped $\mathrm{CuCrO}_{2}$ nanoparticles.

ratio [32]. On the other hand, as can be seen in literature, $\mathrm{TiO}_{2}$ photoanodes fabricated with small-size particles have dense layer and good adherence to FTO substrate [26]. For these reasons, the short-circuit current density and the efficiency of DSSCs fabricated using small particles should be higher than those comprising large particles. However, in our case, the DSSC fabricated with the photoanode B, which consists of $\mathrm{TiO}_{2}$ particles with a size of about $80-180 \mathrm{~nm}$ has higher short-circuit current density and efficiency than the DSSC made from the photoanode A, with the same $\mathrm{TiO}_{2}$ thickness. Our results show that the $\mathrm{TiO}_{2}$ mesoporous layers prepared using small and large $\mathrm{TiO}_{2}$ nanoparticles are difficult to detach from the surface of the FTO glasses. The adherence of $\mathrm{TiO}_{2}^{-}$particles in both the cases is the same and their good adherence to the FTO glasses are in agreement with results reported by Hocevar et al [26,33]. As a result, in our case, the amount of adsorbed dye on the surface of nanoparticles and the adherence of $\mathrm{TiO}_{2}$ nanoparticles to FTO glasses have no predominant effect on the $J_{\mathrm{SC}}$ increment. The $J_{\mathrm{SC}}$ increment can be attributed to the electron transport mechanism. 

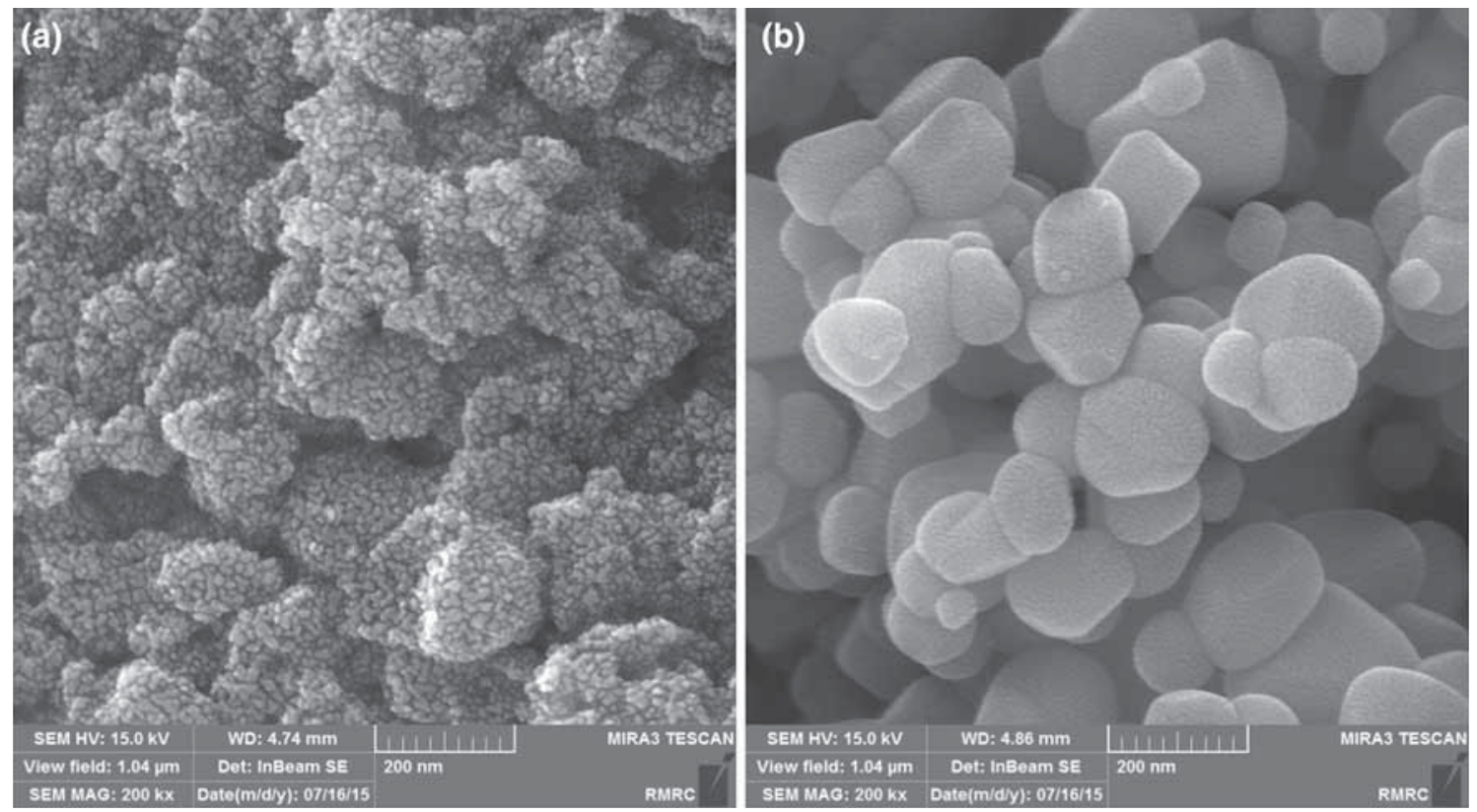

Figure 2. FESEM images of the prepared (a) small-size and (b) large-size $\mathrm{TiO}_{2}$ nanoparticles.

A two-step carrier transport mechanism is mentioned for the electron in $\mathrm{TiO}_{2}$ photoanode. First, electrons diffuse inside one particle and after reaching the surface of the particle they transfer from the particle to the neighbouring one through a neck formed between them. From this vision, larger semiconductor particles and larger neck size are desirable for good electron transport [34,35]. In 2003, Nakade et al [36] showed that the photoanode fabricated with larger $\mathrm{TiO}_{2}$ nanoparticles has suitable resistance to prevent recombination as a result of the longer diffusion length of electrons in the $\mathrm{TiO}_{2}$ nanoparticle film. The increment in diffusion length is attributed to the reduced boundaries such as grain boundary. On the other hand, $\mathrm{TiO}_{2}$ photoanode fabricated with small particles has a nanoporous structure in comparison with that made from large ones. Difficulty in penetration of solid-state electrolyte in nanoporous structure of $\mathrm{TiO}_{2}$ photoanode increases the electron-hole recombination in DSSCs. Therefore, although $\mathrm{TiO}_{2}$ photoanode fabricated with the large-size particles does not have a large surface area for dye adsorption, but the good electron transport and penetration of the large amount of $\mathrm{CuCrO}_{2}$ nanoparticles in the porous structure lead to higher short-circuit current density. The increment in open-circuit voltage can be attributed to the reduction in the electronhole recombination, which can be concluded from fill factor and open-circuit voltage decay measurement. Open-circuit voltage decay measurement is used as a simple and powerful method to study the rate of electron recombination in DSSCs [37]. Zaban et al [38] suggested that the rate of opencircuit voltage decay is inversely related to the lifetime of the light-generated electron in DSSCs and that the lifetime of the electron is inversely related to the rate of recombination. The relationship between voltage decay and charge carrier lifetime is given in equation (1) [38]:

$$
\tau_{n}=\frac{k_{\mathrm{B}} T}{q}\left(\frac{\mathrm{d} V_{\mathrm{oc}}}{\mathrm{d} t}\right)^{-1},
$$

in which $k_{\mathrm{B}}$ is the Boltzmann constant, $T$ is the absolute temperature and $q$ is the positive elementary charge. To measure the open-circuit voltage decay, the simulated solar light is turned off and the decay of photovoltage is recorded. Figure 3c shows the open-circuit voltage decay of the fabricated DSSCs. As can be seen, the decay of the photovoltage for sample A is faster than that of sample B, which indicates that the recombination rate is faster in sample $\mathrm{A}$ in comparison with the other one. Consequently, the enhancement of efficiency is obtained for the $\mathrm{TiO}_{2}$ photoanode fabricated by using the larger particles. The electron lifetimes determined from the open-circuit voltage decay measurements are about $5.1 \mathrm{~ms}$ for small nanoparticles and $6.9 \mathrm{~ms}$ for large nanoparticles at open-circuit voltage (see figure $3 \mathrm{~d}$ ).

To increase the power conversion efficiency we search for the optimal thickness of the photoanode. The thickness of the $\mathrm{TiO}_{2}$ photoanode is controlled by the speed of spin-coating and its value is measured by cross-sectional FESEM (micrographs are not shown). DSSCs fabricated with thin $\mathrm{TiO}_{2}$ layers have low efficiency due to the small amount of adsorbed dye on the surface of mesoporous layer [39]. On the other hand, DSSCs fabricated with thick $\mathrm{TiO}_{2}$ photoanodes have low efficiency due to the recombination phenomena originated from the difficulty in collection of electron because of long distance. Similar problems can happen for solid-state DSSCs as well. Figure 4a displays the $I-V$ characteristic of fabricated DSSCs with different thicknesses. As can be seen, the 

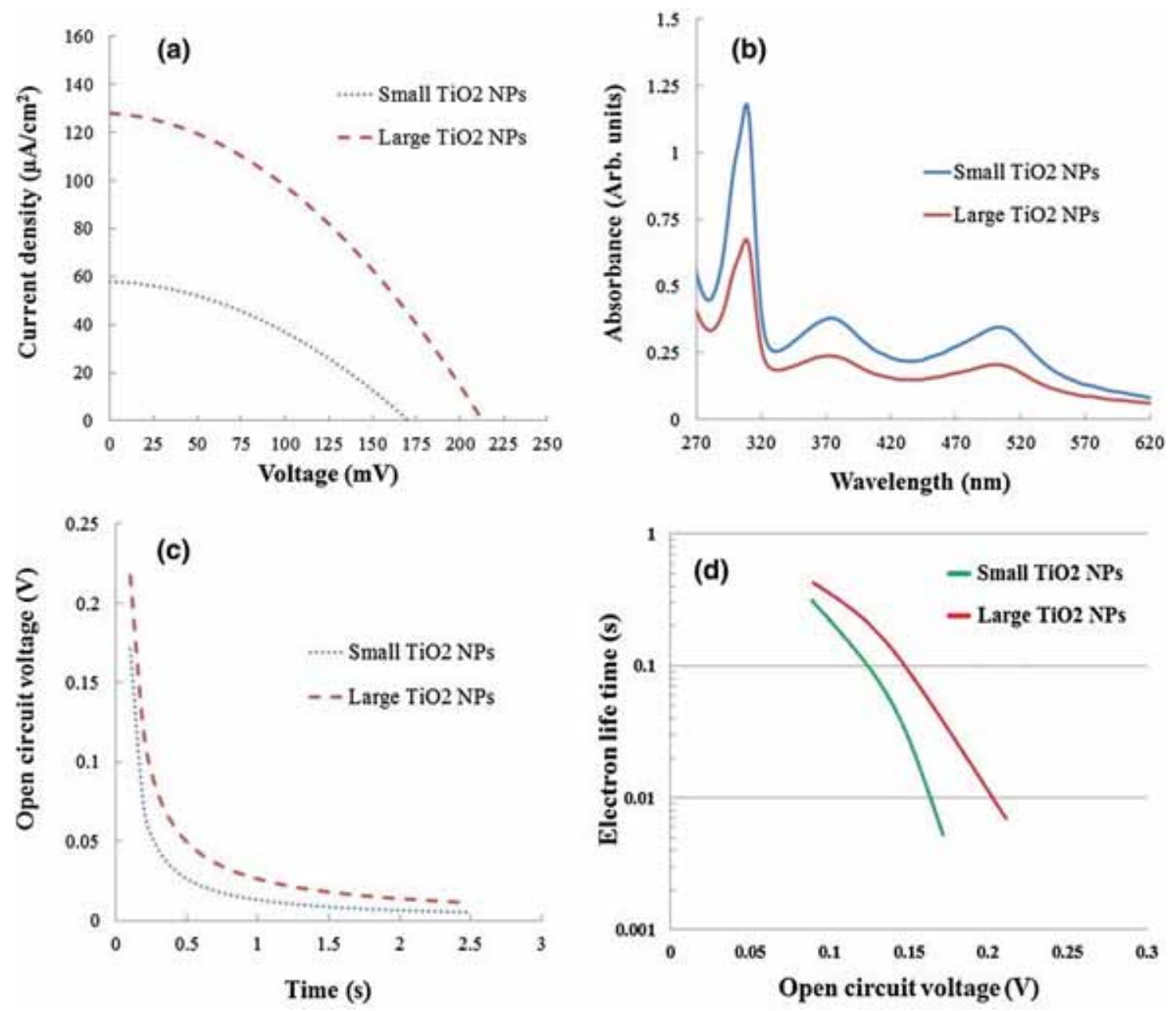

Figure 3. (a) Current density-voltage characteristics of the DSSCs fabricated using $\mathrm{TiO}_{2}$ particles with two different sizes, (b) absorbance spectra of $\mathrm{NaOH}$ solution containing dye molecules desorbed from $\mathrm{TiO}_{2}$ photoanodes, (c) opencircuit voltage $\left(V_{\mathrm{OC}}\right)$ decay of the fabricated DSSCs and $(\mathbf{d})$ calculated electron lifetime as a function of open-circuit voltage.

value of the short-circuit current density increases with the $\mathrm{TiO}_{2}$ layer thickness up to $21 \mu \mathrm{m}$ and then slightly decreases. As the thickness of the $\mathrm{TiO}_{2}$ mesoporous layer increases, the amount of adsorbed dye on the surface of the mesoporous layer increases, which in turn can enhance the number of electron-hole pairs. UV-Vis absorption spectra of desorbed N719 dye from the $\mathrm{TiO}_{2}$ photoanodes with different thicknesses are shown in figure $4 \mathrm{~b}$. Initially, the light-generated carriers can easily be collected at the thinnest photoanode, but $J_{\mathrm{SC}}$ is low due to the small amount of adsorbed dye. For the thickest photoanode, the generated electrons cannot easily be moved to the electron collector. The long distance and recombination of electron-hole pairs are the predominant factors for the reduction of $J_{\mathrm{SC}}$. As a result, the highest values of $J_{\mathrm{SC}}$ and efficiency are obtained for the thickness of $\mathrm{TiO}_{2}$ layer of around $21 \mu \mathrm{m}$. The open-circuit voltage decay measurement shows faster recombination rate for the DSSC fabricated with thickness of about $37 \mu \mathrm{m}$ (see figure 4c). At open-circuit voltage, the derived electron lifetimes from the open-circuit voltage decay measurements are about $6.9,15.2$ and $8.3 \mathrm{~ms}$ for 10,21 and $37 \mu \mathrm{m}$ thick $\mathrm{TiO}_{2}$ photoanodes, respectively.

In the later step, we study the effect of $\mathrm{CuCrO}_{2}$ thickness and $\mathrm{Mg}$ and $\mathrm{Zn}$ doping in $\mathrm{CuCrO}_{2}$ as a solid-state electrolyte. Owing to the difficulty in preparation of bi-layer samples for cross-sectional SEM analysis (a layer of $\mathrm{CuCrO}_{2}$ nanoparticles on the $\mathrm{TiO}_{2}$ paste), we deposited the $\mathrm{CuCrO}_{2}$ nanoparticles on glass substrate in the same condition for preparing the DSSCs and measured their thicknesses (micrographs are not shown). Current-voltage characteristics of the fabricated DSSCs with different thicknesses of solid-state electrolyte are displayed in figure 5a. The results indicate that the efficiency of DSSCs decreases with increase in thickness of $\mathrm{CuCrO}_{2}$ above $4.7 \mu \mathrm{m}$. The reduction in the efficiency of DSSCs may be due to increase in resistivity of $\mathrm{CuCrO}_{2}$ nanoparticles, which is originated from carrier scattering from 

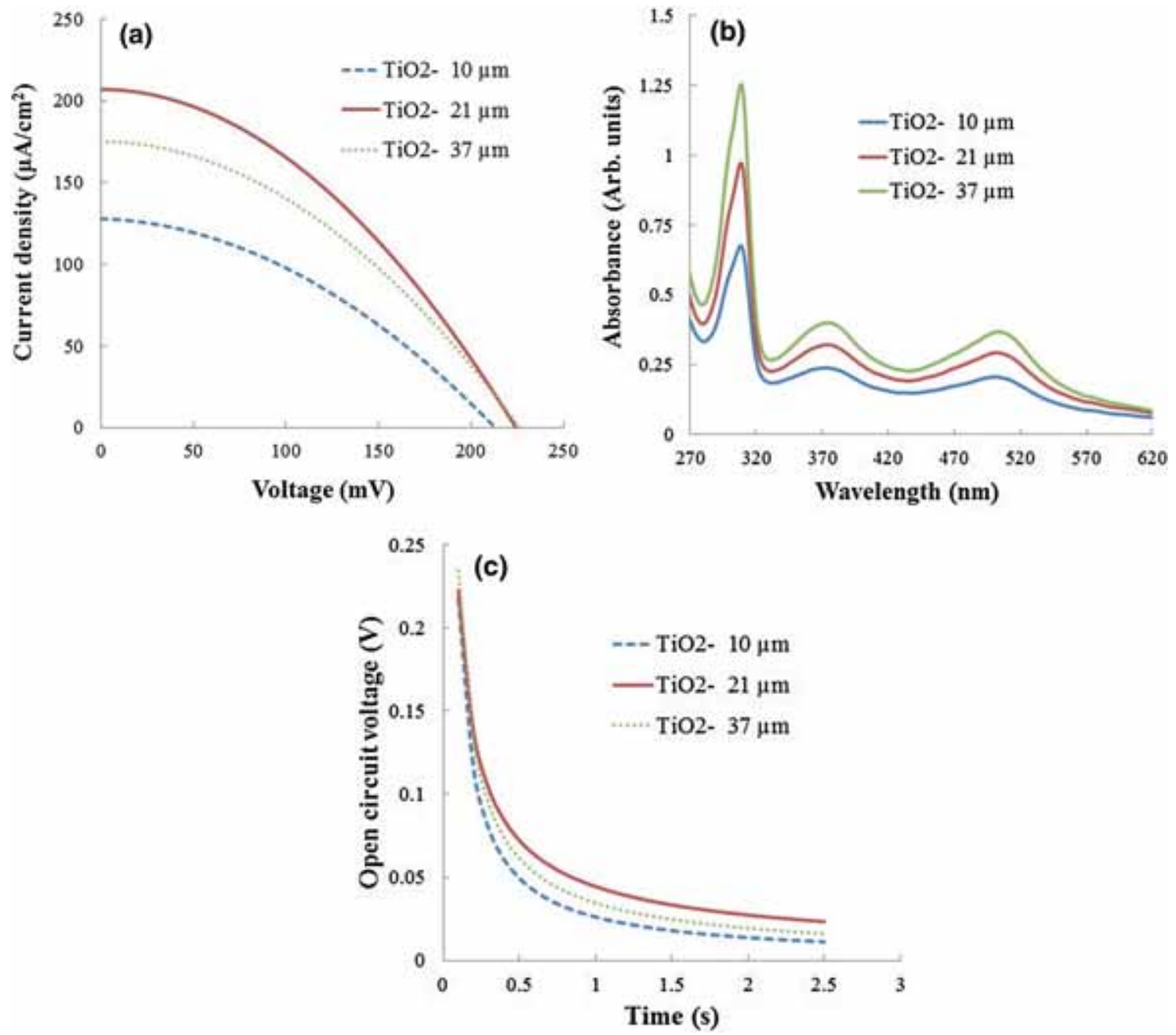

Figure 4. (a) Current density-voltage characteristics of the DSSCs with different thicknesses of $\mathrm{TiO}_{2}$ photoanode, (b) absorbance spectrum of $\mathrm{NaOH}$ solution containing dye molecules, which were desorbed from $\mathrm{TiO}_{2}$ photoanodes and (c) decay of the open-circuit voltage $\left(V_{\mathrm{OC}}\right)$ of the DSSCs with different thicknesses of the $\mathrm{TiO}_{2}$ layer.

particle boundaries. Figure $5 \mathrm{~b}$ shows the open-circuit voltage decay measurement of the fabricated DSSCs. As can be seen, the decay of voltage in the DSSC with $6.5 \mu$ m thick of $\mathrm{CuCrO}_{2}$ solid-state electrolyte is faster than the two others, which indicates that the recombination rate in this DSSC is faster when compared with the others. At open-circuit voltage, the calculated electron lifetimes from the open-circuit voltage decay measurements are about 15.2, 21.3 and $10.3 \mathrm{~ms}$ for 3.5, 4.7 and $6.5 \mu \mathrm{m}$ thick $\mathrm{CuCrO}_{2}$ solid-state electrolyte, respectively.

The current-voltage characteristics of DSSCs for different types of $\mathrm{CuCrO}_{2}$ solid-state electrolytes are shown in figure 6a. Among the constructed devices the $\mathrm{TiO}_{2} / \mathrm{N} 719$ dye $/ \mathrm{CuCrO}_{2}$ solid-state DSSC shows the lowest conversion efficiency, about $0.027 \%$, and the lowest fill factor of $35 \%$. The $J_{\mathrm{SC}}$ is $316 \mu \mathrm{A} \mathrm{cm}^{-2}$ and $V_{\mathrm{OC}}$ is around $0.242 \mathrm{~V}$. From table 1 , we can realize an efficiency increase from $0.027 \%$ for $\mathrm{TiO}_{2} / \mathrm{N} 719$ dye $/ \mathrm{CuCrO}_{2}$ to $0.033 \%$ for $\mathrm{TiO}_{2} / \mathrm{N} 719$ dye/ $\mathrm{CuCrO}_{2}: \mathrm{Zn}$ and further increase to $0.042 \%$ for $\mathrm{TiO}_{2} / \mathrm{N} 719$ dye $/ \mathrm{CuCrO}_{2}: \mathrm{Mg}$. It is noteworthy to see that the doping improves $J_{\mathrm{SC}}, V_{\mathrm{OC}}$ and the efficiency of DSSCs. The increase in $J_{\mathrm{SC}}$ can be attributed to the conductivity enhancement of $\mathrm{CuCrO}_{2}$ nanoparticles. When a small amount of divalent cation is introduced into the $\mathrm{CuCrO}_{2}$ lattice and is placed in the $\mathrm{Cr}^{3+}$ site, electrical conductivity is improved due to the creation of one free-hole. The Hall effect measurement results indicate that the $\mathrm{Mg}$-doped $\mathrm{CuCrO}_{2}$ nanoparticles have large carrier concentration and conductivity in comparison with $\mathrm{Zn}$-doped $\mathrm{CuCrO}_{2}$ nanoparticles at the same dopant concentration (see table 2). The impurity doping also increases the open-circuit voltage. This increase of $V_{\mathrm{OC}}$ may be explained by the difference in the work function of metal-doped $\mathrm{CuCrO}_{2}$ and that of the non-doped one. The $\mathrm{CuCrO}_{2}$ nanoparticles with $\mathrm{Mg}$ doping have a larger work function resulting from a larger hole carrier concentration. With addition of acceptor dopant, the Fermi level $\left(E_{\mathrm{f}}\right)$ moves towards valence-band edge. In this case, the work function $\varphi=E_{\infty}-E_{\mathrm{f}}$ (where 

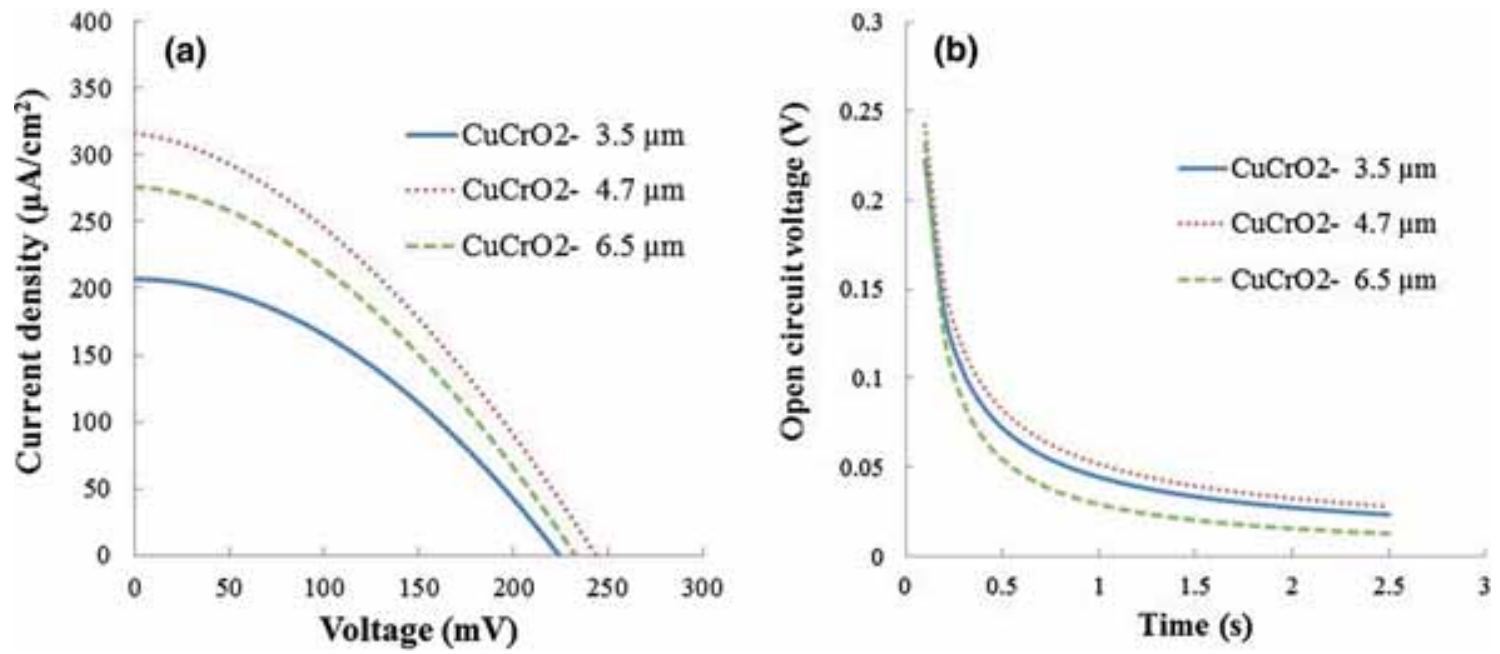

Figure 5. (a) Current density-voltage characteristics and (b) open-circuit voltage decay of the DSSCs with different thicknesses of $\mathrm{CuCrO}_{2}$ hole transport layer.
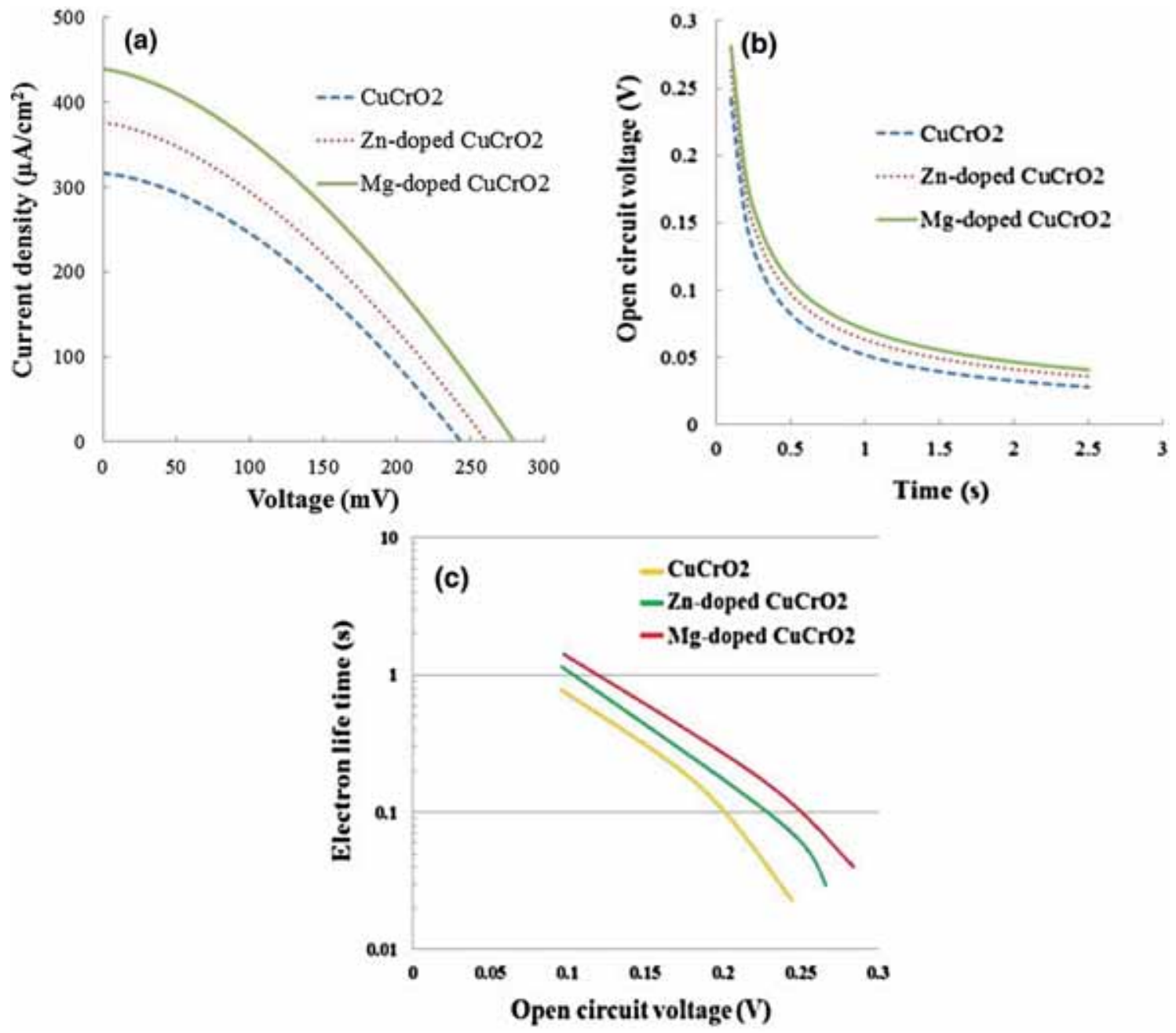

Figure 6. (a) current density-voltage $(J-V)$ plots of cells made from non-doped, $\mathrm{Zn}$ - and $\mathrm{Mg}$-doped $\mathrm{CuCrO}_{2}$ nanoparticles as solid-state electrolytes, (b) open-circuit voltage decay $v$ s. time for different solid-state DSSCs and (c) calculated electron lifetime as a function of open-circuit voltage. 
Table 1. Photovoltaic parameters of the solid-state DSSCs with different dopants in $\mathrm{CuCrO}_{2}$ hole transport layers.

\begin{tabular}{|c|c|c|c|c|}
\hline Sample & $\mathrm{FF}(\%)$ & $J_{\mathrm{SC}}\left(\mu \mathrm{A} \mathrm{cm}^{-2}\right)$ & $V_{\mathrm{OC}}(\mathrm{mV})$ & $\operatorname{PCE}(\%)$ \\
\hline $\mathrm{TiO}_{2} / \mathrm{N} 719$ dye $/ \mathrm{CuCrO}_{2}$ & 35 & 317 & 242 & 0.027 \\
\hline $\mathrm{TiO}_{2} / \mathrm{N} 719$ dye/CuCrO $2: \mathrm{Zn}$ & 34 & 376 & 260 & 0.033 \\
\hline $\mathrm{TiO}_{2} / \mathrm{N} 719$ dye $/ \mathrm{CuCrO}{ }_{2}: \mathrm{Mg}$ & 34 & 440 & 280 & 0.042 \\
\hline
\end{tabular}

Table 2. Hall effect measurement results such as charge carrier concentration, hall mobility and resistivity.

\begin{tabular}{lccc}
\hline Sample & $\mathrm{CuCrO}_{2}$ & $\mathrm{CuCrO}_{2}: \mathrm{Zn}(5 \%)$ & $\mathrm{CuCrO}_{2}: \mathrm{Mg}(5 \%)$ \\
\hline Charge carriers concentration $\left(\mathrm{cm}^{-3}\right)$ & $5.0 \times 10^{16}$ & $4.6 \times 10^{17}$ & $5.3 \times 10^{18}$ \\
Hall mobility $\left(\mathrm{cm}^{2} \mathrm{~V}^{-1} \mathrm{~s}^{-1}\right)$ & 2.7 & 2.4 & 2.2 \\
Resistivity $(\Omega \mathrm{cm})$ & 46.3 & 5.7 & 0.5 \\
\hline
\end{tabular}
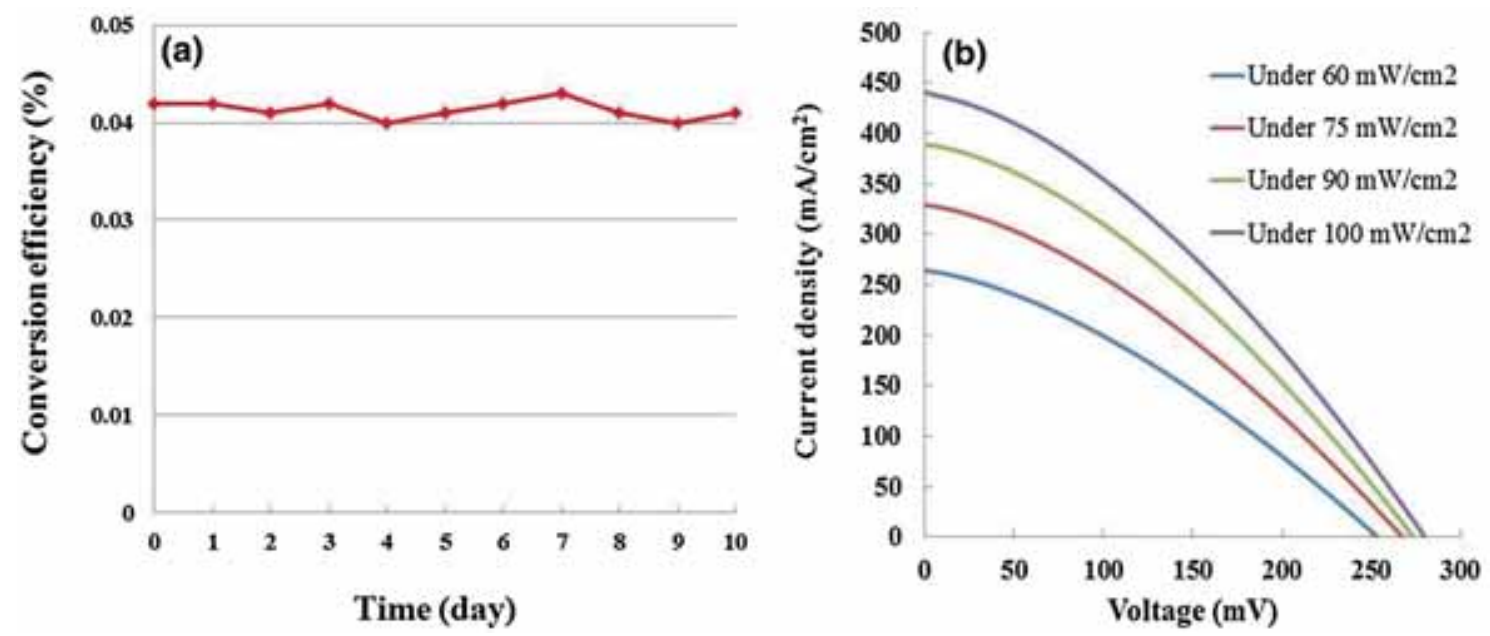

Figure 7. (a) Variation of conversion efficiency as a function of time for the DSSC assembled with $\mathrm{Mg}$-doped $\mathrm{CuCrO}_{2}$ nanoparticles as solid-state electrolyte and (b) current density-voltage curve of solid-state DSSC with $\mathrm{Mg}$-doped CuCrO$_{2}$ nanoparticles under different light intensities.

$E_{\infty}$ is the vacuum energy) is increased. The open-circuit voltage decay measurement shows slower recombination rate for the DSSC fabricated with $\mathrm{Zn}$ - and $\mathrm{Mg}$-doped $\mathrm{CuCrO}_{2}$ nanoparticles (see figure $6 \mathrm{~b}$ ). The slow recombination rate in the DSSCs made from doped $\mathrm{CuCrO}_{2}$ nanoparticles can be attributed to the conductivity improvement in the $\mathrm{CuCrO}_{2}$ nanoparticles. The calculated electron lifetime as a function of open-circuit voltage is shown in figure 6c. The DSSC made from $\mathrm{Mg}$-doped $\mathrm{CuCrO}_{2}$ nanoparticles has longer electron lifetime at open circuit voltage (about $39.5 \mathrm{~ms}$ ) relative to that made from undoped $(21.3 \mathrm{~ms})$ and $\mathrm{Zn}$-doped $\mathrm{CuCrO}_{2}$ nanoparticles (28.9 ms). Zou et al [40] have reported similar results for $\mathrm{FTO} / \mathrm{TiO}_{2} / \mathrm{CdTe} / \mathrm{C}$ structure with energy conversion efficiency of about $0.07 \%$ under AM1.5G illumination $\left(J_{\mathrm{SC}}, V_{\mathrm{OC}}\right.$ and $\mathrm{FF}$ are $0.67 \mathrm{mAcm}^{-2}, 0.65 \mathrm{~V}$ and $17 \%$, respectively). Recently, Pavan et al [41] prepared the $\mathrm{TiO}_{2} / \mathrm{Cu}_{2} \mathrm{O}$ all-oxide heterojunction solar cells by spray pyrolysis method onto FTO glass substrates with short-circuit current density of $0.4 \mathrm{~mA} \mathrm{~cm}^{-2}$ and open-circuit voltage of about $350 \mathrm{mV}$. Furthermore, Yuhas et al [42] have observed photovoltaic properties in $\mathrm{FTO} / \mathrm{ZnO}$ nanowire $/ \mathrm{Cu}_{2} \mathrm{O}$ nanoparticles structure with energy conversion efficiency of about $0.053 \%$ by using $\mathrm{a} \mathrm{TiO}_{2}$ blocking layer.

To study the long-term stability of the solid-state DSSC performance, the conversion efficiency of $\mathrm{TiO}_{2} / \mathrm{N} 719 / \mathrm{Mg}$-doped $\mathrm{CuCrO}_{2}$ device was monitored for a period of 10 days. Figure $7 \mathrm{a}$ exhibits the variation of conversion efficiency as a function of time. From the monitored conversion 
Table 3. Photovoltaic parameters of the solid-state DSSC with $\mathrm{Mg}$-doped $\mathrm{CuCrO}_{2}$ nanoparticles as solid-state electrolyte under different light intensities.

\begin{tabular}{lcccccc}
\hline Light intensity $\left(\mathrm{mW} \mathrm{cm}^{-2}\right)$ & $J_{\mathrm{SC}}\left(\mathrm{mAcm}^{-2}\right)$ & $V_{\mathrm{OC}}(\mathrm{mV})$ & $\mathrm{FF}(\%)$ & PCE $(\%)$ & $\begin{array}{l}\text { Shunt } \\
\text { resistance }(\mathrm{k} \Omega)\end{array}$ & $\begin{array}{l}\text { Series } \\
\text { resistance }(\mathrm{k} \Omega)\end{array}$ \\
\hline 60 & 264 & 254 & 32.8 & 0.037 & 4.0 & 0.63 \\
75 & 330 & 268 & 33.2 & 0.039 & 3.8 & 0.52 \\
90 & 390 & 275 & 33.7 & 0.040 & 3.6 & 0.44 \\
100 & 440 & 280 & 34.0 & 0.042 & 2.0 & 0.39 \\
\hline
\end{tabular}

efficiency variation of the solid-state DSSC we can see that the performance of the DSSC shows no noticeable degradation and stays stable. From these results, it is expected that the $\mathrm{CuCrO}_{2}$ as solid-state electrolyte is a promising candidate for constructing DSSCs with good durability.

To investigate the effect of intensity of light on the performance of the constructed solid-state DSSC, the light intensity has been varied. The obtained results are presented in figure $7 \mathrm{~b}$ and table 3 , which show that $J_{\mathrm{SC}}$ increases with increasing the intensity of incident light. As the intensity of light increases, the number of photons striking per unit area of the DSSC increases and consequently, the number of photogenerated charge carriers grows. As a result the efficiency of the solid-state DSSC increases, which can be attributed to the improvement of shunt and series resistances of the cell under high illumination.

\section{Conclusions}

We have investigated the influence of the $\mathrm{TiO}_{2}$ nanoparticle size, the $\mathrm{TiO}_{2}$ photoanode thickness and the solidstate electrolyte thickness on the photovoltaic properties of $\mathrm{CuCrO}_{2}$-based solid-state DSSCs. We found that although the $\mathrm{TiO}_{2}$ photoanode fabricated with the large-size particles does not have a large surface area for dye adsorption, but good electron transport and penetration of the large amount of $\mathrm{CuCrO}_{2}$ nanoparticles in the porous structure lead to higher short-circuit current density and efficiency. We also improved the photocurrent, photovoltage and power conversion efficiency of the solid-state DSSCs by using doped $\mathrm{CuCrO}_{2}$ nanoparticles. The power conversion efficiency increment in the DSSCs made from $\mathrm{CuCrO}_{2}$ nanoparticles with divalent cations doping is attributed to the low electrical resistivity in comparison with the non-doped $\mathrm{CuCrO}_{2}$ nanoparticles.

\section{Acknowledgements}

We gratefully acknowledge financial support from the Iran National Science Foundation (INSF) under Grant Number 93034818.

\section{References}

[1] Ghani S, Sharif R, Shahzadi S, Zafar N, Anwar A W, Ashraf A et al 2015 J. Mater. Sci. 501469

[2] Anca Dumbrava A, Prodan G, Georgescu A and Moscalu F 2015 Bull. Mater. Sci. 3865

[3] Eshaghi A and Aghaei A A 2015 Bull. Mater. Sci. 381177

[4] Asemi M, Maleki S and Ghanaatshoar M 2017 J. Sol-Gel Sci. Technol. 81645

[5] Xiong D, Xu Z, Zeng X, Zhang W, Chen W, Xu X et al 2012 J. Mater. Chem. 2224760

[6] Xiong D, Zhang W, Zeng X, Xu Z, Chen W, Cui J et al 2013 ChemSusChem. 61432

[7] Zhu S, Shan L, Tian X, Zheng X, Sun D, Liu X et al 2014 Ceram. Int. 4011663

[8] Narayan M R 2012 Renew. Sust. Energ. Rev. 16208

[9] Mathew S, Yella A, Gao P R, Humphry-Baker R, Curchod B F E, Ashari-Astani N et al 2014 Nat. Chem. 6242

[10] Venkatesana S, Sua S C, Kaoa S C, Tenga H and Lee Y L 2015 J. Power Sources 274506

[11] Lan Z, Wu J, Lin J and Huang M 2010 J. Mater. Sci.: Mater. Electron. 211000

[12] Singh P K, Nagarale R K, Pandey S P, Rhee H W and Bhattacharya B 2011 Adv. Nat. Sci.: Nanosci. Nanotechnol. 2 023002

[13] Asemi M and Ghanaatshoar M 2016 Ceram. Int. 426664

[14] Wu J, Lan Z, Lin J, Huang M, Huang Y, Fan L et al 2015 Chem. Rev. 1152136

[15] Somsongkul V, Saekung C, Thang S H, Wongchaisuwat A and Arunchaiya M 2011 Chiang. Mai. J. Sci. 38223

[16] Lie-Hang C, Bo-Fei X, Xi-Zhe L, Ke-Xin L, Yan-Hong L, Qing-Bo M et al 2007 Chin. Phys. Lett. 24555

[17] Li B, Wang L, Kang B, Wang P and Qiu Y 2006 Sol. Energy Mater. Sol. Cells 90549

[18] Perera V P S, Senevirathna M K I, Pitigala P K D D P and Tennakone K 2005 Sol. Energy Mater. Sol. Cells 86443

[19] Premalal E V A, Dematage N and Konno A 2012 Chem. Lett. 41510

[20] Bandara J and Weerasinghe H 2005 Sol. Energy Mater. Sol. Cells $\mathbf{8 5} 385$

[21] Bandara J and Yasomanee J P 2007 Semicond. Sci. Technol. 22 20

[22] Lee Y M, Hsu C H and Chen H W 2009 Appl. Surf. Sci. 255 4658

[23] Lee Y M and Lai C H 2009 Solid-State Electron 531116

[24] Ahmed J, Blakely C K, Prakash J, Bruno S R, Yu M, Wu Y et al 2014 J. Alloys Compd. 591275 
[25] Renaud A, Cario L, Deniard P, Gautron E, Rocquefelte X, Pellegrin Y et al 2014 J. Phys. Chem. C 11854

[26] Hocevar M, Krasovec U O, Berginc M, Drazic G, Hauptman N and Topic M 2008 J. Sol-Gel Sci. Technol. 48156

[27] Hocevar M, Berginc M, Topic M and Krasovec U O $2010 \mathrm{~J}$. Sol-Gel Sci. Technol. $\mathbf{5 3} 647$

[28] Asemi M and Ghanaatshoar M 2014 J. Sol-Gel Sci. Technol. 70416

[29] Yang H, Zhang K, Shi R, Li X, Dong X and Yu Y 2006 J. Alloys Compd. 413302

[30] Dhungel S K, Park C W and Park C W 2013 Himalayan Phys. 427

[31] Jeng M J, Wung Y L, Chang L B and Chow L 2013 Int. J. Photoenergy 20131

[32] Asemi M and Ghanaatshoar M 2016 Appl. Phys. A 122842

[33] Hocevar M, Krasovec U O, Berginc M and Topic M 2010 Acta Chim. Slov. $\mathbf{5 7} 405$
[34] Park K, Zhang Q, Myers D and Cao G 2013 Appl. Mater. Interfaces $\mathbf{5} 1044$

[35] Benko G, Skarman B, Wallenberg R, Hagfeldt A, Sundstrom V and Yartsev A P 2003 J. Phys. Chem. B 1071370

[36] Nakade S, Saito Y, Kubo W, Kitamura T, Wada Y and Yanagida S 2003 J. Phys. Chem. B 1078607

[37] Asemi M and Ghanaatshoar M 2017 J. Mater. Sci. 52489

[38] Bisquert J, Zaban A, Greenshtein M and Mora-Sero I $2004 \mathrm{~J}$. Am. Chem. Soc. 12613550

[39] Baglio V, Girolamo M, Antonucci V and Arico A S 2011 Int. J. Electrochem. Sci. 63375

[40] Zou Y, Li D, Sheng X, Wang L and Yang D 2012 J. Sol. Energy 861359

[41] Pavan M, Rühle S, Ginsburg A, Keller D A, Barad H N, Sberna P M et al 2015 Sol. Energ. Mat. Sol. Cells 132 549

[42] Yuhas B D and Yang P 2009 J. Am. Chem. Soc. 1313756 